引用格式: 刘丽, 褚力其, 姜志德. 技术认知、风险感知对黄土高原农户水土保持耕作技术采用意愿的影响及代际差异 [J]. 资源 科学, 2020, 42(4): 763-775. [Liu L, Chu L Q, Jiang Z D. Influence of technology cognition and risk perception on the willingness to adopt soil and water conservation tillage technologies and its intergenerational differences[J]. Resources Science, 2020, 42(4): 763775. ] DOI: $10.18402 /$ resci.2020.04.14

\title{
技术认知、风险感知对黄土高原农户水土保持 耕作技术采用意愿的影响及代际差异
}

\author{
刘 丽 $^{1,2}$,褚力其 ${ }^{1}$, 姜志德 $^{1}$
}

(1. 西北农林科技大学经济管理学院, 杨凌 712100 ;

2. 山西师范大学历史与旅游文化学院, 临汾 041000)

\begin{abstract}
摘 要: 黄土高原农户对水土保持耕作技术的认知和对水土流失风险的感知是水土保持耕作技术采用意愿的 关键影响因素, 探究二者对技术采用意愿的作用有利于促进农户技术采用率的提高、控制水土流失、减少入黄泥沙 量、改善生态环境。本文利用黄土高原 1237 户农户的调查数据,基于代际差异的视角,采用逐步回归法和分组回归 法, 分析了农户技术认知和风险感知对其水土保持耕作技术采用意愿的影响及代际差异。结果表明: (1)技术认知 对水土保持耕作技术的采用意愿有显著的正向影响, 技术认知对等高耕作、沟垄种植、少免耕、深松耕、秥秆还田、 残茬覆盖和地膜覆盖技术采用意愿的作用强度均是新生代农户大于老一代农户。(2)风险感知对新生代和老一代 农户等高耕作和沟垄种植技术采用意愿均有显著的正向影响,其影响强度存在代际差异; 对新生代农户少免耕技 术采用意愿有显著的正向影响,对老一代农户深松耕、梏秆还田、残茬覆盖和地膜覆盖技术采用意愿有显著的正向 影响。(3)风险感知在技术认知和采用意愿之间发挥正向调节作用,在等高耕作、沟垄种植、残茬覆盖和地膜覆盖技 术采用意愿中，风险感知对于老一代农户的调节作用强于新一代; 在少免耕、深松耕和秥秆还田技术采用意愿中， 风险感知对于新一代农户的调节作用强于老一代。户主年龄、受教育程度、家庭劳动力数量等控制变量对新生代 和老一代农户水土保持耕作技术采用意愿的影响有显著差异。建议农业技术和政策推广视新老农户区别对待, 提 供有针对性的补贴, 并通过鼓励土地流转为技术采用提供便利。
\end{abstract}

关键词: 技术认知; 风险感知;农户;水土保持耕作技术; 采用意愿;代际差异; 黄土高原

DOI :10.18402/resci.2020.04.14

\section{1 引言}

长期以来,水土流失问题威胁人类生存与可持 续发展。中国是世界上水土流失最为严重的国家 之一, 目前中国水土流失面积高达 273.69 万 $\mathrm{km}^{2}$, 特 别是黄土高原地区 57.46 万 $\mathrm{km}^{2}$ 的土地中,水土流失 面积达 21.37 万 $\mathrm{km}^{2}$, 占总面积的 $37.19 \%{ }^{[1]}$ 。水土流 失造成生态环境恶化, 严重的水土流失致使土地生 产力水平低下, 社会经济落后。自新中国成立至 今, 中国一直重视水土流失的治理, 通过修建基本
农田(包括坡改梯)、营造水土保持林和经济果木 林、种草、封禁治理、保土耕作等技术和措施加强治 理 ${ }^{[2]}$ 。黄土高原地区经过多年治理,年人黄泥沙量 由 20 世纪的 16 亿 $\mathrm{t}$ 减少到近年的 3 亿多 $\mathrm{t}^{[3]}$ 。

在水土流失治理实践中,形成了一系列的水土 流失治理技术和措施,包括工程措施、生物措施和 耕作措施 ${ }^{[4,5]}$ 。工程措施和生物措施的实施中, 政府 是主体, 农户只是参与其中; 耕作措施的实施中, 农 户是主体, 能够根据自身需要和意愿主动进行技术

收稿日期: 2019-07-15 修订日期: 2019-10-11

基金项目: 山西省社科联项目(SSKLZDKT2019054); 国家重点研发计划项目(2016YFC0503703)。

作者简介: 刘丽,女, 山西临汾人,博士生, 资源经济与环境管理方向。E-mail: esabellyliuli@hotmail.com

通讯作者:姜志德,男,重庆人,教授,资源经济与环境管理方向。E-mail: zhidej@sina.com 
选择,政府负责技术推广。农户作为基本的生产单 元, 是水土保持技术和措施的直接采用者和受益 者。特别是水土保持耕作技术, 农户将其应用在农 业生产中, 与传统耕作技术相比, 显著减少了径流 冲刷, 改良了土壤、增加了农业产量。中共中央、国 务院印发的《乡村振兴战略规划 (2018-2022)》 》[6] 指出, 要推进水土流失治理, 要求尊重农民意愿, 切 实发挥农民主体作用，避免代替农民选择。因此， 在 “绿水青山就是金山银山”建设中,应用和推广水 土保持耕作技术，成为治理水土流失的必然选择。 但是在中国广大农村地区, 农户对水土保持耕作技 术认知程度差, 采用意愿不高, 采用率较低 ${ }^{[2,7]}$, 这一 现实阻碍了水土保持耕作技术推广。同时, 随着农 村改革和劳动力市场的发展, 加之农业机械化水平 的提升, 大量农村居民从农业劳动中分离出来, 进 城务工, 农户对土地依赖程度和土地价值认知改 变, 尤其是代际之间差异明显, 导致技术采用的差 异。为提高农户水土保持耕作技术采用意愿进而 促进技术采用, 需要探讨农户技术认知和风险感知 对其水土保持耕作技术的采用意愿及代际差异, 为 水土保持耕作技术的进一步推广提供科学依据。

已有的技术认知对农户技术采用意愿的影响 研究中, 认为技术认知包括技术收益性认知、技术 有效性认知、技术易操作性认知、技术内在感知、技 术服务效果感知等 ${ }^{[8,9,10]}$ 。近年来多从感知易用性和 感知有用性方面进行衡量技术认知 ${ }^{[1]}$, 对技术认知 正向影响技术采用意愿基本达成共识。已有的风 险感知对农户技术采用意愿的影响方面, 并未达成 共识。多数研究认为风险感知与农户意愿正相 关 ${ }^{[12,13,14]}$, 还有一些研究发现二者之间负相关 ${ }^{[15]}$ 。以 上研究中都将农户作为同质性样本, 没有考虑不同 代际农户行为的差异。而目前中国农村地区务农 农户的代际分化显著,不同代际农户在个人特征、 职业、收人、观念等方面的差异, 导致其行为差异 ${ }^{[16,17]}$ 。 近年来学者将其引人相关领域的研究, 包括农户生 计、生态耕种、土地流转、耕地保护等 ${ }^{[18,19,20]}$ 。费红梅 等 ${ }^{[21]}$ 和曹慧等 ${ }^{[22]}$ 从代际差异视角出发, 研究了不同 农户群体保护性耕作技术的采用意愿。在水土保 持技术采用意愿的研究中, 较多关注个人特征 ${ }^{[23]}$ 、家 庭特征 ${ }^{[24]}$ 、社会规范 ${ }^{[25]}$ 、成本 (包括机会成本、风险成

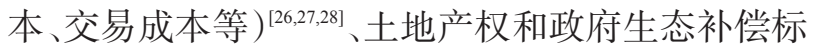

准和形式 ${ }^{[6,29]}$ 等对退耕还林参与意愿的影响。

上述研究在技术认知、风险感知及代际差异对 农户行为意愿的影响方面成果颇丰, 为本文的研究 奠定了基础,但还有可以拓展的空间。首先,在水 土保持技术研究中, 没有学者专门针对水土保持耕 作技术的农户采用意愿进行相关研究。其次,技术 认知或风险感知是影响人的行为的重要因素, 很多 文献中都有涉及, 仅限于单独分析, 没有将二者纳 人同一理论框架中,更缺乏二者交互作用的影响。 在技术认知的研究中, 或者关注技术本身,或者关 注技术效果。技术认知是主体对技术的了解程度, 包括对技术本质、属性、特征、功能等多方面的认 识。因此本文的技术认知综合了农户对技术本身、 技术便利性和技术功能效果的认知, 分析其对技术 采用意愿的影响。最后,在农户个人特征对水土保 持技术采用意愿分析中,多数研究忽视了不同农户 群体采用意愿的差异。特别是在目前, 随着经济社 会发展, 中国农村务农劳动力的代际分化十分明 显, 务农主体特征有显著差异, 新生代农户与老一 代农户之间在耕作方式和技术选择上存在明显差 异 ${ }^{[30,31]}$ 。鉴于此,本文以黄土高原山西、陕西和甘肃 3 省 6 县 1237 户农户为例, 以调查区域中水土保持 耕作措施的核心技术(包括等高耕作、沟垄种植、少 免耕、深松耕、秸秆还田、残茬覆盖、地膜覆盖)的采 用意愿为研究对象,分析农户技术认知和风险感知 对其水土保持耕作技术采用意愿的影响,并探究不 同代际农户技术采用意愿的差异和原因, 旨在为黄 土高原地区水土流失治理提供理论支持和政策 建议。

\section{2 理论基础与研究假设}

\section{1 技术认知对水土保持耕作技术采用意愿的影响}

根据计划行为理论的研究,主体的认知会影响 其意愿进而影响其行为决策。技术认知属于人的 心理因素,行为经济学认为人类的决策行为会受到 心理因素的影响 ${ }^{[32]}$ 。农户是否愿意采用水土保持耕 作技术，也取决于其对该项技术的认知程度。首 先, 农户对技术本身的认知, 如是否听说过该项技 术、是否见过他人采用该项技术,会影响农户的采 用意愿; 其次还需要考虑技术使用的便利性,包括 技术是否容易掌握、使用是否方便、机械是否容易 租赁等; 最后还要考虑农户对技术功能或效果的认 
知,包括增产增收、改善土地肥力、缓解土壤板结、 控制水土流失、改善生态环境等。水土保持耕作措 施包括多项技术,农户对不同技术的认知程度有所 差异。农户对技术本身、技术便利性和效果的认知 水平会影响其技术采用意愿, 认知水平越高技术采 用意愿越强烈。由此,本文提出下列假设:

$\mathrm{H} 1$ : 技术认知对农户水土保持耕作技术的采用 意愿有显著的正向影响。

\section{2 风险感知对农户水土保持耕作技术采用意愿的 影响}

风险感知是个体在面临决策时, 对不确定因素 的识别 ${ }^{[33]}$ 。风险主体在感知到风险的情况下, 会做 出相应的反应 ${ }^{[34]}$ 。因此, 风险感知在个体决策中发 挥了重要的影响作用,可以作为决策的解释变量。 以往相关研究表明, 在农户行为决策中, 风险感知 对于其行为有正向作用 ${ }^{[35,36]}$ 。具体到水土保持耕作 技术, 在决定是否采用技术之前, 农户首先会对水 土流失带来的风险进行判断, 具体包括对当地水土 流失严重程度的判断, 对水土流失破坏耕地的风险 的判断, 对水土流失造成减产风险的判断等方面。 为减少水土流失带来的耕地破坏和减产的风险,农 户愿意采用水土保持耕作技术。由此,本文提出下 列假设：

$\mathrm{H} 2$ : 风险感知对农户水土保持耕作技术的采用 意愿有显著的正向影响。

\section{3 不同代际农户水土保持耕作技术采用意愿的 分析}

随着经济社会发展, 中国农村务农劳动力的代 际分化十分明显, 新生代农户与老一代农户之间在 耕作方式和技术选择上存在明显差异。不同代际 农户, 由于处于生命周期的不同阶段,其自身的受
教育程度、收人水平、消费观念、信息来源等方面存 在明显的差别 ${ }^{[27,37]}$, 这些都会影响其技术认知和风 险感知,进而影响其水土保持耕作技术采用意愿。 对于不同水土保持耕作技术而言,农户技术认知的 差异导致技术采用意愿的差异。本文在划分农户 代际方面,借鉴刘炎周 ${ }^{[38}$ 的做法,按照户主的出生年 份, 将农户划分为新生代和老一代两种类型, 其中 1975 年以后出生的为新生代, 1975 年之前出生的农 户为老一代。鉴于以上分析, 本文提出以下假设:

$\mathrm{H} 3$ : 技术认知和风险感知对不同代际农户的水 土保持耕作技术采用意愿的影响存在显著差异。

\section{3 数据来源与变量设置}

\section{1 数据来源}

黄土高原幅员辽阔，包含山西、陕西、甘肃、青 海、宁夏、内蒙古和河南7省(区)287县,这些地区由 于气温、水分、地貌的差异,形成了不同的耕作制 度 ${ }^{[39]}$ 。在充分考虑水土保持耕作技术在各区之间差 异的基础上,采用分层随机抽样法,首先根据文献 中黄土高原水土流失状况确定水土流失最为严重 的省 (区), 每个省选择两个县, 最终选取了汾渭平 原半湿润区的山西省汾阳市和吉县, 黄土丘陵区的 陕西省安塞区和靖边县,黄土残塬丘陵区的甘肃省 镇原县和泾川县作为研究区域。课题组于 2019 年 1-3 月对山西省、陕西省和甘肃省 6 个县(市、区) 的 农户进行抽样调查, 每个县选择 2 3 个镇。每个镇 随机选择 3 5 个村, 每个村随机抽取 1 25 户农户， 样本分布见表 1 。调研农户 1316 户, 得到有效问卷 1237 份, 问卷有效率为 $94 \%$ 。

\section{2 变量设置}

\subsection{1 因变量}

本文选择水土保持耕作措施的核心技术,包括

表 1 研究区域样本农户分布情况

Table 1 Distribution of sample farmers in the study area

\begin{tabular}{|c|c|c|c|c|}
\hline 省份 & 县(市或区) & 乡(镇) & 样本数/户 & 比例/\% \\
\hline \multirow[t]{2}{*}{ 山西省 } & 吉县 & 屯里镇、城关镇、柏山寺乡 & 244 & 19.73 \\
\hline & 汾阳市 & 演武镇、肖家庄镇 & 196 & 15.84 \\
\hline \multirow[t]{2}{*}{ 陕西省 } & 安塞区 & 真武洞镇、沿河湾镇、化子坪镇 & 215 & 17.38 \\
\hline & 靖边县 & 东坑镇、杨桥畔镇、龙洲镇 & 203 & 16.42 \\
\hline \multirow[t]{2}{*}{ 甘肃省 } & 镇原县 & 城关镇、屯字镇、上肖乡 & 197 & 15.92 \\
\hline & 泾川县 & 城关镇、玉都镇、 & 182 & 14.71 \\
\hline 合计 & - & - & 1237 & 100.00 \\
\hline
\end{tabular}


少免耕、深松耕、等高耕作、沟垄种植、覆盖耕作 (残 茬覆盖、秸秆还田、地膜覆盖）。分析农户水土保持 耕作技术的采用意愿时, 首先利用二元赋值法度量 农户是否采用的问题, 0 表示农户不愿采用某项技 术, 1 表示农户愿意采用该项技术。

表 2 显示了样本农户的水土保持耕作技术采用 意愿情况。在所调查的农户中, 老一代农户为 925 户，占总样本的 $74.78 \%$, 符合中国目前农村的实际 情况, 即农业劳动力趋于老龄化。总的来看, 在水 土保持耕作技术中, 少免耕、深松耕和秸秆还田技 术的采用意愿相对较高,其他技术采用意愿较低。

\subsection{2 核心自变量}

(1)技术认知

本文将农户的水土保持耕作技术认知分为三 大类。一是对技术本身的认知, 通过 “您是否听说 过该技术”这一问题来体现; 二是技术便利性认知， 通过“该技术容易掌握”“该技术使用方便”“该技术 有配套的机具” 等 3 个问题体现; 三是技术效果认 知, 通过“该技术能提高产量” “该技术能增加农业 收人”“该技术能提高土壤肥力”“该技术能缓解土 壤板结”“该技术能控制水土流失”“该技术能改善 生态环境”等问题来体现。

(2) 风险感知

农户对水土流失的风险感知包括 3 个方面,一 是本地水土流失严重程度的感知, 通过 “您认为本 地水土流失情况如何” 来体现; 二是水土流失破坏 耕地的风险判断, 通过 “您家耕地受到水土流失影 响面积大吗”来体现; 三是水土流失造成的作物减 产的风险判断, 通过 “水土流失对减产的影响大吗” 这一问题体现。

\section{表 2 水土保持耕作技术采用意愿及其代际分布}

Table 2 Adoption intention and intergenerational distribution of soil and water conservation tillage technology

\begin{tabular}{|c|c|c|c|c|}
\hline \multirow{2}{*}{$\begin{array}{l}\text { 水土保持 } \\
\text { 耕作技术 }\end{array}$} & \multicolumn{2}{|c|}{ 新生代 } & \multicolumn{2}{|c|}{ 老一代 } \\
\hline & 愿意/户 & 不愿意/户 & 愿意/户 & 不愿意/户 \\
\hline 等高耕作 & 120 & 192 & 375 & 550 \\
\hline 沟垄种植 & 88 & 224 & 352 & 573 \\
\hline 少免耕 & 128 & 184 & 431 & 494 \\
\hline 深松耕 & 157 & 155 & 501 & 424 \\
\hline 秸秆还田 & 176 & 136 & 540 & 385 \\
\hline 残茬覆盖 & 94 & 218 & 346 & 579 \\
\hline 地膜覆盖 & 113 & 199 & 374 & 551 \\
\hline
\end{tabular}

\subsection{3 控制变量}

控制变量中,选取了户主年龄和受教育程度反 映农户的个体特征; 家庭劳动力数量和非农收人占 家庭总收人的比重反映农户家庭特征; 实际耕种土 地面积反映土地情况; 村庄到城镇的距离和交通是 否便利反映村庄特征。

各变量的定义、赋值及描述性统计见表 3 。

\section{3 模型设定}

农户是否愿意采用某一项水土保持耕作技术 的行为 $(Y)$ 是一个二元分类变量, 为因变量, 赋值为 0 或 1,0 表示不愿意, 1 表示愿意。自变量包括技术 认知、风险感知和控制变量 3 个方面。假设农户是 理性的经济人, 其从利益最大化原则出发,进行技 术决策。在大样本条件下,利用二元 Logistic 离散 回归模型, 对农户采用水土保持耕作技术的意愿进 行拟合。模型设定如下：

$$
\begin{gathered}
y_{1 j}=\alpha_{0 j}+\alpha_{i j} v_{i}+\varepsilon_{1 j} \\
y_{2 j}=\beta_{0 j}+\beta_{1 j} x_{1 j}+\beta_{i j} v_{i}+\varepsilon_{2 j} \\
y_{3 j}=\lambda_{0 j}+\lambda_{1 j} x_{1 j}+\lambda_{2 j} x_{2 j}+\lambda_{i j} v_{i}+\varepsilon_{3 j} \\
y_{4 j}=\eta_{0 j}+\eta_{1 j} x_{1 j}+\eta_{2 j} x_{2 j}+\eta_{3 j} x_{1 j} \cdot x_{2 j}+\eta_{i j} v_{i}+\varepsilon_{4 j}
\end{gathered}
$$

式中: $y$ 表示技术采用意愿, $j=1,2, \cdots, 7$,表示不同的 水土保持耕作技术; $v_{i}$ 为控制变量,包括户主年龄、 受教育程度、家庭劳动力数量、非农收人占家庭总 收人比重、实际耕种土地面积、村庄到城镇的距离 和交通便利性; $x_{1 j} 、 x_{2 j} 、 x_{1 j} \cdot x_{2 j}$ 分别表示为技术认知 和、风险感知及二者交互项; $\alpha 、 \beta 、 \lambda$ 和 $\eta$ 分别为相 应变量的回归系数; $\varepsilon$ 为随机误差项。

首先利用 SPSS 20.0 检验所有的自变量之间是 否具有多重共线性,结果发现方差膨胀因子均小于 2 , 因此变量满足独立性原则, 变量之间不存在严重 的共线性问题, 可以进行回归分析。分别以等高耕 作、沟垄种植、少免耕、深松耕、秸秆还田、残茬覆盖 和地膜覆盖 7 项水土保持耕作技术农户的采用意愿 作为因变量, 同时考虑到采用意愿的代际差异,进 行逐步回归和分组回归。由于农户技术认知和风 险感知涉及到多个维度, 本文根据研究需要将各个 维度的观测值进行加权平均, 得到技术认知和风险 感知得分。式 (1) 只放人控制变量, 式(2)在式 (1) 的基础上放人技术认知变量,式(3)在式(2)的基础 上放人风险感知变量, 最后式 (4)考察技术认知和 风险感知交互项的影响, 分析风险感知的调节作 
表 3 采用意愿、技术认知和风险感知各变量设定及赋值

Table 3 Variable definition and values of willingness, technology cognition, and risk perception

\begin{tabular}{|c|c|c|}
\hline 变量 & 变量名 & 定义与赋值 \\
\hline \multirow[t]{7}{*}{ 因变量 } & 等高耕作采用意愿 & 尓愿意采用该技术吗？不愿意 $=0$; 愿意 $=1$ \\
\hline & 沟垄种植采用意愿 & \\
\hline & 少免耕采用意愿 & \\
\hline & 深松耕采用意愿 & \\
\hline & 秸秆还田采用意愿 & \\
\hline & 残茬覆盖采用意愿 & \\
\hline & 地膜覆盖采用意愿 & \\
\hline \multirow[t]{14}{*}{ 核心自变量 } & 技术认知 & \\
\hline & 技术本身认知 & 是否听说过该技术? \\
\hline & 技术便利性认知 & 不同意 $=1$; 不太同意 $=2 ;$ 一般 $=3$; 比较同意 $=4$; 同意 $=5$ \\
\hline & & 不同意 $=1$; 不太同意 $=2$; 一般 $=3$; 比较同意 $=4$; 同意 $=5$ \\
\hline & & 该技术有配套的机具 不同意 $=1$; 不太同意 $=2$; 一般 $=3$; 比较同意 $=4$; 同意 $=5$ \\
\hline & 技术效果认知 & 该技术能提高产量 $\quad$ 不同意 $=1$; 不太同意 $=2$; 一般 $=3$; 比较同意 $=4$; 同意 $=5$ \\
\hline & & 该技术能增加农业收人 不同意 $=1$; 不太同意 $=2 ;$ 一般 $=3$; 比较同意 $=4$; 同意 $=5$ \\
\hline & & 该技术能提高土壤肥力 不同意 $=1$; 不太同意 $=2$; 一般 $=3$; 比较同意 $=4$; 同意 $=5$ \\
\hline & & 该技术能缓解土壤板结 不同意 $=1$; 不太同意 $=2$; 一般 $=3$; 比较同意 $=4$; 同意 $=5$ \\
\hline & & 该技术能控制水土流失 不同意 $=1$; 不太同意 $=2 ;$ 一般 $=3$; 比较同意 $=4$; 同意 $=5$ \\
\hline & & 该技术能改善生态环境 不同意 $=1$; 不太同意 $=2$; 一般 $=3$; 比较同意 $=4$; 同意 $=5$ \\
\hline & 风险感知 & 您认为本地水土流失情况如何 无水土流失 $=1$; 不太严重 $=2$; 一般 $=3$; 比较严重 $=4$; 非常严重 $=5$ \\
\hline & & 您家耕地受到水土流失影响面积大吗 无影响 $=1$; 不太大 $=2$; 一般 $=3$; 比较大 $=4$; 非常大 $=5$ \\
\hline & & 无影响 $=1$; 不太大 $=2 ;$ 一般 $=3$; 比较大 $=4$; 非常大 $=5$ \\
\hline \multirow[t]{7}{*}{ 控制变量 } & 个人特征 & 户主年龄/岁 \\
\hline & & 没上过学 $=1$; 小学 $=2$; 初中 $=3$; 高中 $/$ 中专 $=4$; 大专及以上 $=5$ \\
\hline & 家庭特征 & 家庭劳动力数量/人 \\
\hline & & 非农收人占家庭总收入比重 $20 \%$ 以下 $=1 ; 21 \% \sim 50 \%=2 ; 51 \% \sim 80 \%=3 ; 81 \%$ 以上 $=4$ \\
\hline & 土地特征 & 实际耕种土地面积/亩 \\
\hline & 村庄特征 & 村庄到城镇距离 $/ \mathrm{km}$ \\
\hline & & 很不方便=1; 不太方便=2;一般=3; 比较方便=4; 非常方便=5 \\
\hline
\end{tabular}

用,最终比较拟合效果进行结果分析。选取指标 -2 loglikelihood、LR $c h i^{2} 、 P r o b>c h i^{2}$ 和 Nagelkerke $R^{2}$ 来衡量模型拟合效果, 其中-2 loglikelihood 是-2 倍 的对数似然函数的值, 数值越小模型拟合效果越 好; $\mathrm{LR} c h i^{2}$ 为卡方检验统计量, $P r o b>c h i^{2}$ 为其 $P$ 值, LR $c h i^{2}$ 越大, $P$ 值越小, 模型显著性越好, 反之越差; Nagelkerke $R^{2}$ 为广义决定系数, 数值越大模型的解 释能力越强。

\section{4 结果与分析}

表 4-6 给出了不同代际农户水土保持耕作技术 采用意愿对应式 (1)、（2）、（3）的模型 1 、模型 2 、模型 3 的回归结果, 表 7 给出了对应式(4)的风险感知调 节作用的结果, 这里仅报告技术认知和风险感知交
互项的回归结果。由回归结果可知, 逐步加人技术 认知、风险感知和交互项后, 模型拟合效果变好, 说 明技术认知、风险感知和交互项对技术采用意有重 要影响。

\section{1 技术认知的影响}

由表 4-6 可知, 技术认知对农户水土保持耕作 技术的采用意愿均有显著的正向影响。无论是新 生代农户还是老一代农户，随着技术认知程度的提 高,更愿意采用水土保持耕作技术。

根据模型 2 的回归结果, 从代际角度来看, 对于 等高耕作、沟垄种植、少免耕、深松耕、秸秆还田、残 茬覆盖和地膜覆盖技术的认知对新生代农户技术 采用意愿的影响系数分别为 $1.875 、 2.952 、 1.879$ 、 


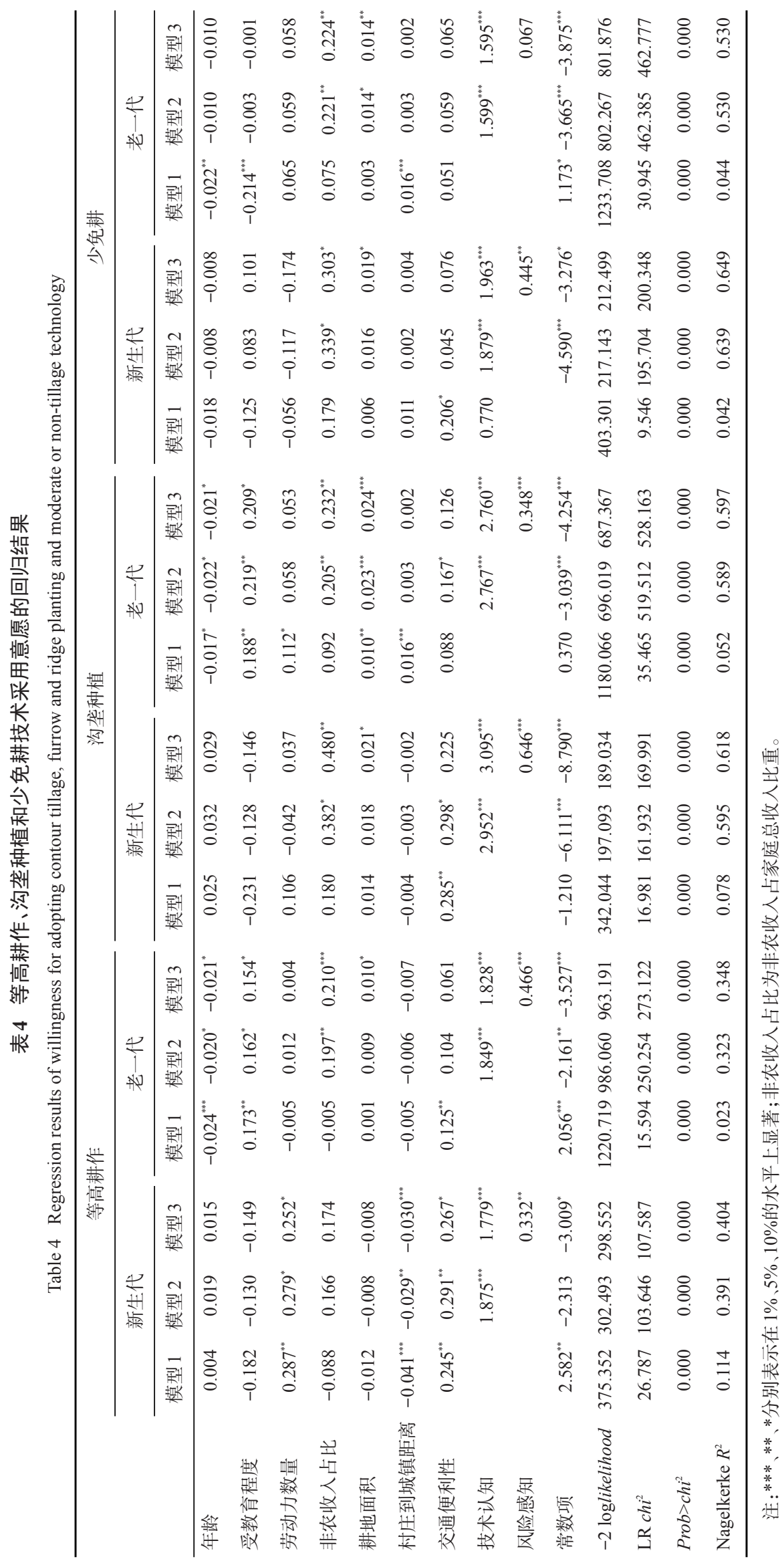


表 5 深松耕和秸秆还田技术采用意愿的回归结果

Table 5 Regression results of willingness for adopting subsoiling and straw returning technology

\begin{tabular}{|c|c|c|c|c|c|c|c|c|c|c|c|c|}
\hline & \multicolumn{6}{|c|}{ 深松耕 } & \multicolumn{6}{|c|}{ 秸秆还田 } \\
\hline & \multicolumn{3}{|c|}{ 新生代 } & \multicolumn{3}{|c|}{ 老一代 } & \multicolumn{3}{|c|}{ 新生代 } & \multicolumn{3}{|c|}{ 老一代 } \\
\hline & 模型 1 & 模型 2 & 模型 3 & 模型 1 & 模型 2 & 模型 3 & 模型 1 & 模型 2 & 模型 3 & 模型 1 & 模型 2 & 模型 3 \\
\hline 户主年龄 & 0.025 & 0.012 & 0.012 & 0.003 & 0.007 & 0.008 & 0.004 & -0.006 & -0.006 & 0.010 & -0.007 & -0.006 \\
\hline 户主受教育程度 & $0.329^{* *}$ & 0.108 & 0.106 & 0.051 & $0.226^{* *}$ & $0.221^{* *}$ & 0.207 & -0.236 & -0.227 & 0.115 & -0.119 & -0.116 \\
\hline 家庭劳动力数量 & -0.068 & 0.031 & 0.036 & 0.043 & 0.039 & 0.036 & -0.136 & -0.064 & -0.080 & 0.032 & 0.083 & 0.082 \\
\hline 非农收人占比 & $0.464^{* * *}$ & $0.459^{* * *}$ & $0.469^{* *}$ & $0.167^{* * *}$ & 0.071 & 0.082 & $0.366^{* * *}$ & $0.456^{*}$ & $0.436^{*}$ & 0.091 & $0.228^{* *}$ & $0.249^{* *}$ \\
\hline 耕种土地面积 & -0.013 & 0.004 & 0.004 & 0.001 & $0.022^{* * * *}$ & $0.023^{* * *}$ & -0.001 & 0.008 & 0.007 & 0.005 & 0.010 & 0.012 \\
\hline 村庄到城镇距离 & $-0.020^{* *}$ & -0.021 & -0.021 & $-0.019^{* * *}$ & $-0.011^{*}$ & $-0.011^{*}$ & $-0.021^{* *}$ & -0.023 & -0.024 & $-0.010^{* *}$ & $-0.011^{*}$ & $-0.012^{*}$ \\
\hline 交通便利性 & -0.126 & $-0.302^{*}$ & -0.293 & 0.048 & -0.148 & -0.123 & -0.138 & -0.336 & -0.353 & 0.038 & $-0.171^{*}$ & -0.139 \\
\hline 技术认知 & & $2.645^{* * * *}$ & $2.662^{* * *}$ & & $2.249^{* * * * *}$ & $2.288^{* * * *}$ & & $2.798^{* k * k * k}$ & $2.756^{* * * *}$ & -0.878 & $2.100^{* * * *}$ & $2.143^{* * *}$ \\
\hline 常数项 & $-2.118^{*}$ & $-5.117^{* * * *}$ & $-5.390^{* *}$ & -0.549 & $-3.306^{* * * *}$ & $-4.289^{* * *}$ & -0.303 & -3.434 & $-2.742^{*}$ & & $-2.887^{* * *}$ & $-4.094^{* * *}$ \\
\hline$-2 \log$ likelihood & 392.039 & 171.126 & 171.025 & 1231.726 & 636.393 & 631.838 & 398.831 & 137.394 & 136.961 & 1227.055 & 638.694 & 631.668 \\
\hline $\mathrm{LR} c h i^{2}$ & 30.777 & 251.691 & 251.791 & 29.554 & 624.886 & 629.442 & 18.988 & 280.425 & 280.858 & 14.332 & 602.693 & 609.719 \\
\hline Prob $>c h i^{2}$ & 0.000 & 0.000 & 0.000 & 0.000 & 0.000 & 0.000 & 0.000 & 0.000 & 0.000 & 0.000 & 0.000 & 0.000 \\
\hline Nagelkerke $R^{2}$ & 0.128 & 0.749 & 0.749 & 0.042 & 0.662 & 0.664 & 0.081 & 0.806 & 0.807 & 0.021 & 0.650 & 0.653 \\
\hline
\end{tabular}

表 6 残茬覆盖和地膜覆盖技术采用意愿的回归结果

Table 6 Regression results of willingness for adopting stubble mulching and plastic film covering technology

\begin{tabular}{|c|c|c|c|c|c|c|c|c|c|c|c|c|}
\hline & \multicolumn{6}{|c|}{ 残茬覆盖 } & \multicolumn{6}{|c|}{ 地膜覆盖 } \\
\hline & \multicolumn{3}{|c|}{ 新生代 } & \multicolumn{3}{|c|}{ 老一代 } & \multicolumn{3}{|c|}{ 新生代 } & \multicolumn{3}{|c|}{ 老一代 } \\
\hline & 模型 1 & 模型 2 & 模型 3 & 模型 1 & 模型 2 & 模型 3 & 模型 1 & 模型 2 & 模型 3 & 模型 1 & 模型 2 & 模型 3 \\
\hline 户主年龄 & $0.040^{*}$ & 0.035 & 0.034 & 0.003 & -0.013 & -0.012 & 0.013 & -0.008 & -0.010 & 0.001 & -0.007 & -0.006 \\
\hline 户主受教育程度 & 0.105 & 0.284 & 0.281 & -0.036 & -0.020 & -0.021 & 0.137 & $0.440^{*}$ & $0.453^{* *}$ & $0.244^{* * *}$ & $0.194^{*}$ & $0.189^{*}$ \\
\hline 家庭劳动力数量 & 0.054 & $0.493^{*}$ & $0.475^{*}$ & $0.276^{* * *}$ & 0.087 & 0.092 & -0.001 & $-0.330^{*}$ & -0.307 & $0.162^{* *}$ & -0.033 & -0.035 \\
\hline 非农收人占比 & $0.411^{* * * *}$ & 0.271 & 0.273 & $0.254^{* * *}$ & -0.030 & -0.015 & $0.424^{* * *}$ & $0.572^{* * *}$ & $0.589^{* * *}$ & $0.147^{* *}$ & $0.263^{* * *}$ & $0.282^{* * *}$ \\
\hline 耕种土地面积 & 0.006 & -0.015 & -0.014 & $0.015^{* * * *}$ & 0.001 & 0.002 & 0.010 & $0.024^{* *}$ & $0.025^{* *}$ & 0.007 & $0.017^{* *}$ & $0.017^{* *}$ \\
\hline 村庄到城镇距离 & $-0.022^{* *}$ & -0.013 & -0.014 & $-0.013^{* * *}$ & -0.002 & -0.003 & 0.007 & -0.018 & -0.018 & 0.003 & -0.008 & -0.009 \\
\hline 交通便利性 & -0.054 & -0.337 & -0.329 & 0.015 & $0.213^{* *}$ & $0.183^{*}$ & $-0.213^{*}$ & -0.225 & -0.214 & $0.168^{* * * *}$ & $0.237^{* * *}$ & $0.199^{* *}$ \\
\hline 技术认知 & & $4.009^{* * * * *}$ & $4.010^{* * *}$ & & $3.691^{* * * *}$ & $3.655^{* * *}$ & & $3.177^{* * * k}$ & $3.188^{* * * *}$ & & $3.020^{k \text { knk }}$ & $3.019^{* * *}$ \\
\hline 常数项 & $-3.740^{* * *}$ & $-6.996^{* * *}$ & $-7.291^{* *}$ & $-1.985^{* * *}$ & $-4.195^{* * *}$ & $-5.119^{* * *}$ & -1.526 & $-3.960^{* *}$ & $-4.410^{* *}$ & -0.182 & $-3.812^{* * *}$ & $-4.964^{* * * *}$ \\
\hline -2 loglikelihood & 341.473 & 125.014 & 124.900 & 1152.927 & 516.813 & 513.185 & 377.509 & 189.842 & 189.345 & 1199.493 & 683.330 & 675.812 \\
\hline $\mathrm{LR} c h i^{2}$ & 23.210 & 239.668 & 239.782 & 57.006 & 693.720 & 693.348 & 20.147 & 207.814 & 208.310 & 34.510 & 550.674 & 558.191 \\
\hline Prob $>c h i^{2}$ & 0.000 & 0.000 & 0.000 & 0.000 & 0.000 & 0.000 & 0.000 & 0.000 & 0.000 & 0.000 & 0.000 & 0.000 \\
\hline Nagelkerke $R^{2}$ & 0.105 & 0.780 & 0.781 & 0.083 & 0.724 & 0.727 & 0.088 & 0.678 & 0.679 & 0.050 & 0.611 & 0.617 \\
\hline
\end{tabular}

$2.645 、 2.798 、 4.009$ 和 3.177 ,技术认知对老一代农户 技术采用意愿的影响系数分别为 $1.849 、 2.767$ 、 $1.599 、 2.249 、 2.100 、 3.691$ 和 3.020 。由此可知, 技术 认知对 7 项水土保持耕作技术采用意愿的作用强度 均是新生代农户大于老一代农户。新生代农户普
遍受教育程度高于老一代农户,加之他们更多的时 间在城市从事非农业就业, 能够接受到更多的信 息,其中也包括水土保持耕作技术方面的信息，因 此对技术认知程度要高于老一代农户。同时,新生 代农户的兼业水平较高,家庭收人一般高于老一代 
农户, 其农业种植的机会成本高, 并不愿在农业劳 动上花费太多时间, 因此对于机械化水平较高的技 术采用意愿强烈。假设 $\mathrm{H} 1$ 和 $\mathrm{H} 3$ 得到验证。

\section{2 风险感知的影响}

由表 4-6 可知, 风险感知对水土保持耕作技术 采用意愿的影响,在新生代农户和老一代农户之间 有显著差异, 对各项技术的采用意愿的影响也不 尽相同。

根据模型 3 的回归结果, 风险感知对新生代和 老一代等高耕作技术采用意愿均有显著的正向影 响, 其中对新生代的影响系数为 0.332 , 对老一代农 户的影响系数为 0.466 , 老一代农户的风险感知对采 用意愿的作用强度高于新生代农户。可能的原因 是老一代农户经历过严重的水土流失, 对水土流失 的危害感受更为深刻。特别是在自然灾害发生时, 水土流失加剧, 陡坡耕地被破坏, 造成了作物减 产。虽然经过多年的治理, 老一代农户认为水土流 失问题依然比较严重, 等高耕作技术在治理水土流 失方面意义重大。因此, 风险感知对老一代农户水 土保持耕作技术采用意愿的影响更为强烈。

风险感知对新生代和老一代沟垄种植技术采 用意愿有显著的正向影响, 其中对新生代的影响系 数为 0.646 , 对老一代农户的影响系数为 0.348 , 新生 代农户的风险感知对采用意愿的作用强度高于老 一代农户。可能的解释是沟垄种植技术一般应用 于马铃薯、蔬菜、瓜果、杂粮等经济作物的种植, 老 一代农户认为黄土高原地区水源稀缺, 没有灌溉设 施, 不适合种植经济作物。新生代农户通过互联网 获取信息,加上政府扶持, 同时种植经济作物收人 远高于粮食, 愿意种植经济作物。经济作物的投人 高, 新生代农户对风险感知程度较高, 为了防止水
土流失对作物产量和收人的影响, 其沟垄种植技术 采用意愿较高。

风险感知对新生代农户少免耕技术的采用意 愿有显著的正向影响,影响系数为 0.445 , 而对老一 代农户的采用意愿的影响不显著。少免耕技术不 用犁、耙耕地、整地, 直接在茬地上播种, 播种作物 后不进行中耕,并配合化学除草剂来灭草。老一代 农户认为不翻耕土地, 土壤过于紧实,不利于作物 出苗和生长, 同时病虫害和多年生杂草较多, 虽然 其水土流失的风险感知程度高, 但不愿意采用少免 耕技术。由于少免耕往往配合化学除草, 能够节约 劳动时间, 降低农业生产投人, 因此新生代农户的 技术采用意愿较高。

深松耕、秸秆还田、残茬覆盖和地膜覆盖技术 采用意愿中, 风险感知对老一代农户有显著的正向 影响, 影响系数分别为 $0.261 、 0.325 、 0.269$ 和 0.333 , 而对新生代农户影响不显著。可能的解释是新生 代农户对深松耕、秸秆还田、残茬覆盖和地膜覆盖 技术采用意愿都较高,并不是主要受风险感知的影 响。目前中国这 4 项技术配套的机械较为完善,新 生代农户更加关注机械使用的便利性,因此其技术 采用意愿较高。老一代农户其水土流失风险感知 程度较高,在调查中发现多数地区深松耕技术由政 府免费提供服务, 地膜覆盖技术中用到的地膜, 政 府提供价格或实物补贴; 老一代认为, 秸秆还田技 术和残茬覆盖技术能够有效的控制水土流失。因 此风险感知对老一代农户采用这 4 项技术有显著的 正向影响。

假设 H2 得到部分验证,假设 H3 得到验证。

\section{3 技术认知与风险感知交互的影响}

由表 7 可知,技术认知和风险感知交互项对新

表 7 风险感知的调节作用回归结果

Table 7 Regression results of moderating effect of risk perception

\begin{tabular}{|c|c|c|c|c|c|c|c|c|c|c|c|c|c|c|}
\hline & \multicolumn{2}{|c|}{ 等高耕作 } & \multicolumn{2}{|c|}{ 沟垄种植 } & \multicolumn{2}{|c|}{ 少免耕 } & \multicolumn{2}{|c|}{ 深松耕 } & \multicolumn{2}{|c|}{ 秸秆还田 } & \multicolumn{2}{|c|}{ 残茬覆盖 } & \multicolumn{2}{|c|}{ 地膜覆盖 } \\
\hline & 新生代 & 老一代 & 新生代 & 老一代 & 新生代 & 老一代 & 新生代 & 老一代 & 新生代 & 老一代 & 新生代 & 老一代 & 新生代 & 老一代 \\
\hline $\begin{array}{l}\text { 技术认知× } \\
\text { 风险感知 }\end{array}$ & $0.248^{* * *}$ & $0.249^{*}$ & $0.238^{* * * *}$ & $0.329^{* * *}$ & $0.687^{* * *}$ & $0.472^{* * * *}$ & $0.360^{* *}$ & $0.084^{*}$ & $0.341^{* *}$ & $0.071^{* *}$ & $0.529^{*}$ & $0.534^{*}$ & $0.497^{* *}$ & $0.867^{* * * *}$ \\
\hline $\begin{array}{l}-2 \log \text { like- } \\
\text { lihood }\end{array}$ & 292.811 & 961.044 & 175.423 & 686.026 & 201.560 & 782.746 & 170.279 & 631.600 & 136.214 & 631.458 & 124.219 & 510.656 & 188.555 & 663.236 \\
\hline LR $c h i^{2}$ & 108.328 & 275.269 & 183.602 & 529.504 & 211.287 & 481.906 & 252.538 & 629.679 & 281.606 & 609.929 & 240.463 & 699.877 & 209.101 & 570.768 \\
\hline Prob $>c h i^{2}$ & 0.000 & 0.000 & 0.000 & 0.000 & 0.000 & 0.000 & 0.000 & 0.000 & 0.000 & 0.000 & 0.000 & 0.000 & 0.000 & 0.000 \\
\hline $\begin{array}{l}\text { Nagel- } \\
\text { kerke } R^{2}\end{array}$ & 0.406 & 0.351 & 0.654 & 0.598 & 0.674 & 0.547 & 0.751 & 0.665 & 0.808 & 0.655 & 0.782 & 0.729 & 0.681 & 0.627 \\
\hline
\end{tabular}


生代和老一代农户水土保持耕作技术的采用意愿 均有显著的正向影响。在技术认知相同的情况下， 风险感知越强烈, 技术采用意愿越高, 风险感知在 技术认知和采用意愿之间发挥正向调节作用。在 等高耕作、沟垄种植、残茬覆盖和地膜覆盖技术采 用意愿中,新生代农户风险感知的调节作用系数分 别为 $0.248 、 0.238 、 0.529$ 和 0.497 , 老一代农户风险感 知的调节作用系数分别为 $0.249 、 0.329 、 0.534$ 和 0.867 , 风险感知对于老一代农户的调节作用强于新 一代农户。在少免耕、深松耕和秸秆还田技术采用 意愿中, 新生代农户风险感知的调节作用系数分别 为 $0.687 、 0.360$ 和 0.341 , 老一代农户风险感知的调 节作用系数分别为 $0.472 、 0.084$ 和 0.071 , 风险感知 对于新生代农户的调节作用强于老一代农户。

\section{4 控制变量的影响}

控制变量中, 对于新生代农户而言, 受教育程 度对其地膜覆盖技术采用意愿有显著的正向影响， 地膜覆盖技术具有良好的蓄水保墒作用, 受教育程 度越高的新生代农户对技术效果有明确的认知, 愿 意采用技术。家庭劳动力数量对新生代农户等高 耕作和残茬覆盖技术采用意愿有显著的正向影 响。由于缺乏配套机械, 采用等高耕作技术需要投 人更多劳动力, 家庭劳动力较多的新生代农户愿意 采用等高耕作技术。残茬覆盖技术的机械化操作 水平高, 很多新生代农户外出务工, 愿意采用技术 来减少劳动时间投人。非农收人占家庭总收人比 重对新生代农户沟垄种植、少免耕、深松耕、秸秆还 田和地膜覆盖技术采用意愿有显著的正向影响, 这 5 项水土保持耕作技术的机械化水平较高, 非农收 人占家庭收人越高的新生代农户, 往往更多的时间 从事非农就业, 且能够获得较高的收人, 为节约农 业劳动投人, 愿意承担机械使用费用, 进而采用技 术。实际耕种土地面积对新生代农户沟垄种植、少 免耕和地膜覆盖技术采用意愿有显著的正向影响， 实际耕种面积越大的农户, 能够从农业中获得的收 人越高, 且这 3 项技术的机械操作需要在更大面积 上才能展开。村庄到城镇的距离对新生代农户等 高耕作技术采用意愿有显著的负向影响, 等高耕作 技术原本操作的便利性较差, 加上偏远的村庄在交 通和信息方面都较为落后, 新生代农户采用意愿
低。交通便利性对新生代农户等高耕作技术采用 意愿有显著的正向影响,交通便利性使得与等高耕 作技术配套的小型机械容易进地,因此正向作用于 农户的技术采用意愿。

对于老一代农户而言,户主年龄对其等高耕作 和沟垄种植技术采用意愿有显著的负向影响。老 一代农户经历过黄土高原地区严重的水土流失时 期,对等高耕作技术蓄水保土的作用认可度高, 因 此愿意采用技术。老一代农户种植马铃薯,一般是 为了自用, 为提高产量, 愿意采用沟垄种植技术。 受教育程度对老一代农户等高耕作、沟垄种植、深 松耕和地膜覆盖技术采用意愿有显著的正向影 响。老一代农户观念较为保守, 等高耕作和沟垄种 植技术采用多年,效果明显,农户愿意继续采用; 深 松耕和地膜覆盖技术相对较新, 只有受教育程度高 的农户对技术认知水平较高,采用意愿强。非农收 人占家庭总收人比重对老一代农户等高耕作、沟垄 种植、少免耕、秸秆还田和地膜覆盖技术采用意愿 有显著的正向影响。老一代农户关注采用技术的 投人,非农收人高的农户一般家庭总收人也较高， 能够承担采用技术的成本。实际耕种面积对老一 代农户等高耕作、沟垄种植、少免耕、深松耕和地膜 覆盖技术采用意愿有显著的正向影响。实际耕种 面积越大的农户, 能够从耕地中获得较高的收益, 因此愿意采用技术。村庄到城镇的距离对老一代 农户深松耕和秸秆还田技术采用意愿有显著的负 向影响,这两项技术相对较新且需要机械操作, 偏 远村庄获取技术信息相对不易，因此对技术认知程 度低。同时机械购买费用高, 不是所有村庄都有机 械,加上交通不方便,机械化水平低,农户不愿意采 用技术。交通便利性对老一代农户残茬覆盖和地 膜覆盖技术采用意愿有显著的正向影响,这两项技 术机械化水平高, 交通便利的村庄机械容易进地。

\section{5 结论与建议}

\section{1 结论}

本文利用黄土高原 3 省 6 县 1237 户农户的调查 数据, 基于代际差异的视角, 采用 Logistic 模型, 分 析了农户技术认知和风险感知对其水土保持耕作 技术采用意愿的影响,主要结论如下：

(1)技术认知对农户水土保持耕作技术的采用 
意愿均有显著的正向影响, 无论是新生代农户还是 老一代农户, 随着技术认知程度的提高, 其采用水 土保持耕作技术的意愿也提升, 验证了本文的假设 $\mathrm{H} 1$ 。从代际角度来看, 技术认知对等高耕作、沟垄 种植、少免等、深松耕、秸秆还田、残茬覆盖和地膜 覆盖 7 项水土保持耕作技术采用意愿的作用强度均 是新生代农户大于老一代农户。

(2) 风险感知对老一代农户等高耕作技术采用 意愿的作用强度高于新生代农户; 风险感知对新生 代农户沟垄种植技术采用意愿的作用强度高于老 一代农户; 风险感知对新生代农户少免耕技术采用 意愿有显著的正向影响,而对老一代农户的影响不 显著; 风险感知对老一代农户采用深松耕、秸秆还 田、残茬覆盖和地膜覆盖技术的意愿有显著的正向 影响,对新生代农户影响不显著。

(3) 风险感知在新生代和老一代农户的技术认 知和采用意愿之间发挥正向调节作用。在等高耕 作、沟垄种植、残茬覆盖和地膜覆盖技术采用意愿 中, 风险感知对于老一代农户的调节作用强于新生 代农户; 在少免耕、深松耕和秸秆还田技术采用意 愿中, 风险感知对于新生代农户的调节作用强于老 一代农户。

(4)控制变量对新生代和老一代农户的影响存 在明显差异。其中,户主年龄负向影响老一代农户 等高耕作和沟垄种植技术采用意愿; 户主受教育程 度正向影响新生代农户地膜覆盖采用意愿和老一 代农户等高耕作、沟垄种植、深松耕、地膜覆盖采用 意愿; 家庭劳动力数量正向影响新生代农户等高耕 作和残茬覆盖采用意愿; 非农收人占家庭总收人比 重正向影响新生代农户沟垄种植、少免耕、深松耕、 秸秆还田、地膜覆盖采用意愿和老一代农户等高耕 作、沟垄种植、少免耕、秸秆还田、地膜覆盖采用意 愿。实际耕种土地面积正向影响新生代农户沟垄 种植、少免耕和地膜覆盖技术的采用意愿, 其对对 老一代农户等高耕作、沟垄种植、少免耕、深松耕、 地膜覆盖技术的采用意愿也有正向影响。村庄到 城镇距离负向影响新生代农户等高耕作技术的采 用意愿, 其对老一代农户深松耕和秸秆还田技术的 采用意愿也有负向影响。交通便利性正向影响新 生代农户等高耕作技术的采用意愿, 其对老一代农 户残茬覆盖和地膜覆盖技术的采用意愿也有正向
影响。

\section{2 建议}

在目前生态文明建设背景下, 为提高农户水土 保持耕作技术采用意愿进而积极采用技术,达到控 制水土流失的目的, 需要提高农户技术认知, 鼓励 农户通过采用水土保持耕作技术规避风险, 本文建 议如下：

(1)农业技术推广部门应加强对农户的技术推 广,让农户认识到各项水土保持耕作技术的功能和 作用，了解技术适用情况以及可能带来的问题，同 时可以通过示范基地带动。尤其是对老一代农户， 可通过广播、宣传栏等形式进行技术宣传,提升农 户对技术的认知水平。

(2)加快研发和推广适用水土保持耕作技术的 机具, 同时加大对农户的技术培训力度, 尤其是老 一代农户。鼓励农户加入农机合作社, 通过合作组 织方式,提高农户的水土保持耕作技术的采用意识。

(3)政府要根据不同代际农户的风险感知特 点,制定有针对性的鼓励采用水土保持耕作技术的 补贴数量及补贴形式。特别是对新生代农户,对其 进行水土流失风险进行宣传和培训, 提升其风险认 知水平,进而提高其技术采用意愿。

(4)在目前水土保持耕作技术采用意愿的影响 因素中,耕地规模有显著的正向影响。因此要推动 土地流转,解决耕地细碎化问题,为农户采用现有的 水土保持耕作技术和未来的新技术提供便利条件。

\section{参考文献(References):}

[1] 中华人民共和国水利部. 中国水土保持公报 2018[EB/OL]. (2019-08-20) [2019-10-11]. http://www.mwr.gov.cn/sj/tjgb/zgstbcgb/201908/t20190820_1353674.html. [Ministry of Water Resources of the People's Republic of China. China Water and Soil Conservation Bulletin 2018[EB/OL]. (2019- 08-20) [2019- 1011]. http://www.mwr.gov.cn/sj/tjgb/zgstbegb/201908/t20190820_ 1353674.html.]

[2] 李宗善, 杨否, 王国梁, 等. 黄土高原水土流失治理现状、问题及 对策[J]. 生态学报, 2019, 39(20): 7398-7409. [Li Z S, Yang L, Wang G L, et al. The management of soil and water conservation in the Loess Plateau of China: Present situations, problems, and counter-solutions[J]. Acta Ecologica Sinica, 2019, 39(20): 73987409.]

[3] 中华人民共和国水利部. 中国河流泥沙公报 2018[M]. 北京: 中 
国水利水电出版社, 2018. [Ministry of Water Resources of the People's Republic of China. China River Sediment Bulletin 2018 [M]. Beijing: China Water \& Power Press, 2018.]

[4] 李占斌, 朱冰冰, 李鹏, 等. 土壤侵蚀与水土保持研究进展 [J]. 土 壤学报, 2008, 45(5): 802-809. [Li Z B, Zhu B B, Li P, et al. Advancement in study on soil erosion and soil and water conservation [J]. Acta Pedologica Sinica, 2008, 45(5): 802-809.]

[5] 孙鸿烈. 我国水土流失问题与防治对策[J]. 中国水利, 2011, (6): 16. [Sun H L. Water loss and soil erosion in China and measures for their prevention and control[J]. China Water Resources, 2011, (6): 16.]

[6] 中共中央国务院. 乡村振兴战略规划(2018-2022)[M]. 北京: 人 民出版社, 2018. [State Council of the Central Committee of the Communist Party of China. Strategic Plan for Rural Revitalization (2018-2022)[M]. Beijing: People's Publishing House, 2018.]

[ 7 ] Willy D K, Zhunusova E, Holm-Müller K. Estimating the joint effect of multiple soil conservation practices: A case study of small holder farmers in the lake Naivasha Basin, Kenya[J]. Land Use Policy, 2014, 39(7): 177-187.

[8] Batte M T, Arnholt M W. Precision arming adoption and use in Ohio: Case studies of six leading-edge adopters[J]. Computers and Electronics in Agriculture, 2003, 38(2): 125-139.

[9] 朱月季, 周德翼, 游良志. 非洲农户资源禀赋、内在感知对技术 采纳的影响: 基于埃塞俄比亚奥罗米亚州的农户调查[J]. 资源 科学, 2015, 37(8): 1629-1638. [Zhu Y J, Zhou D Y, You L Z. Impact of farmers' resource endowment and inner perception on technology adoption in Oromia, Ethiopia[J]. Resources Science, 2015, 37(8): 1629-1638.]

[10] 石洪景. 农户采纳台湾农业技术行为及其影响因素分析: 基于 制度及其认知视角的分析[J]. 湖南农业大学学报(社会科学 版), 2015, 16(1): 25-30. [Shi H J. Farmers' Taiwan agricultural technology adoption behavior and its influence factors: Based on system and farmers' cognition[J]. Journal of Hunan Agricultural University (Social Sciences), 2015, 16(1): 25-30.]

[11] 徐涛, 赵敏娟, 李二辉, 等. 技术认知、补贴政策对农户不同节水 技术采用阶段的影响分析[J]. 资源科学, 2018, 40(4): 809-817.

[Xu T, Zhao M J, Li E H, et al. The impact of technology perception and subsidy policy on different phases of farmers' water-saving irrigation technology adoption[J]. Resources Science, 2018, 40 (4): 809-817.]

[12] 孙蓉, 费友海. 风险认知、利益互动与农业保险制度变迁: 基于 四川试点的实证分析 [J]. 财贸经济, 2009, (6): 35-40. [Sun R, Fei Y H. Risk perception, Interest interaction and institutional change of agricultural insurance: An empirical analysis of pilot program in Sichuan Province[J]. Finance \& Trade Economics, 2009, (6): 35-40.]

[13] 邱波. 我国沿海地区农业巨灾风险保障需求研究: 来自浙江省
308 户农民的调查数据[J]. 农业经济问题, 2017, 38(11): 100107. [Qiu B. A study on demand of agriculture catastrophe risk guarantee in China's coastal areas: Based on research data from 308 peasant in Zhejiang Province[J]. Issues in Agricultural Economy, 2017, 38(11): 100-107.]

[14] 向丽, 胡珑瑛. 生计风险感知对农民参与电商扶贫意愿的影响 及代际差异研究[J]. 农业技术经济, 2019, (5): 85-98. [Xiang L, Hu L Y. Study on the impact of livelihood risk perception on farmers' willingness to participate in $\mathrm{e}^{-}$commerce poverty alleviation and its intergenerational differences[J]. Journal of Agrotechnical Economics, 2019, (5): 85-98.]

[15] 谢治菊. 西部地区. 农民对农村社会的风险感知与行为选择[J]. 南京农业大学学报(社会科学版), 2013, 13(4): 12-21. [Xie Z J. Peasants' risk perception and behavior choice for rural social risks in China's western regions[J]. Journal of Nanjing Agricultural University (Social Sciences Edition), 2013, 13(4): 12-21.]

[16] 何军. 代际差异视角下农民工城市融人的影响因素分析[J]. 中 国农村经济, 2011, (6): 15-25. [He J. Analysis on influencing factors of urban integration of migrant workers from the perspective of intergenerational differences[J]. Chinese Rural Economy, 2011, (6): 15-25.]

[17] 黄祖辉, 刘雅萍. 农民工就业代际差异研究: 基于杭州市浙江籍 农民工就业状况调查[J]. 农业经济问题, 2008, (10): 51-59. [Huang Z H, Liu Y P. Study on the generational differences in the employment of migrant workers: Based on the employment survey of migrant workers from Zhejiang in Hangzhou City[J]. Issues in Agricultural Economy, 2008, (10): 51-59.]

[18] 胡江霞, 文传浩. 社会网络、风险识别能力与农村移民可持续生 计: 基于代际差异视角[J]. 技术经济, 2017, 36(4): 110-116. [Hu J X, Wen C H. Social network, risk identification capability and sustainable livelihood of rural migrants: Based on perspective of intergenerational difference[J]. Technology Economics, 2017, 36 (4): 110-116.]

[19] 陈美球, 袁东波, 广佛缘, 等. 农户分化、代际差异对生态耕种采 纳度的影响[J]. 中国人口・资源与环境, 2019, 29(2): 79-86. [Chen M Q, Yuan D B, Kuang F Y, et al. Household differentiation, generational difference and ecological farming adoption[J]. China Population, Resources and Environment, 2019, 29(2): 7986.]

[20] 陈奕山, 钟甫宁. 代际差异、长期非农收人与耕地转出稳定性 [J]. 南京农业大学学报(社会科学版), 2017, 17(3): 112-120. [Chen Y S, Zhong F N. Generation difference, long-term non-agriculture income and rural household's stable transfer-out of contract land[J]. Journal of Nanjing Agricultural University (Social Sciences Edition), 2017, 17(3): 112-120.]

[21] 费红梅, 刘文明, 姜会明. 保护性耕作技术采纳意愿及群体差异 性分析[J. 农村经济, 2019, (4): 122-129. [Fei H M, Liu W M, Ji- 
ang H M. Analysis on adoption willingness and population difference of conservation tillage technology[J]. Rural Economy, 2019, (4): 122-129.]

[22] 曹慧, 赵凯. 代际差异视角下粮农保护性耕作投人意愿的影响 因素分析[J]. 西北农林科技大学学报(社会科学版), 2018, 18 (1): 115-123. [Cao H, Zhao K. Influencing factors of grain farmers' willingness of arable land conservation input: Based on perspective of intergenerational differences[J]. Journal of Northwest A\&F University (Social Science Edition), 2018, 18(1): 115-123.]

[23] 冯琳, 徐建英, 邸敬涵. 三峡生态屏障区农户退耕受偿意愿的调 查分析[J]. 中国环境科学, 2013, 33(5): 938-944. [Feng L, Xu J Y, Di J H. Household's willingness to accept about conversion of farmland into forest program in ecological barrier zone of Three Gorges Reservoir Area[J]. China Environmental Science, 2013, 33 (5): 938-944.]

[24] Liang Y C, Li S Z, Feldman M W, et al. Does household composition matter? The impact of the Grain for Green Program on rural livelihoods in China[J]. Ecological Economics, 2012, 75: 152160.

[25] Chen X D, Lu F, He G M, et al. Linking social norms to efficient conservation investment in payments for ecosystem services[J]. Proceedings of the National Academy of Sciences of the United States of America, 2009, 106(28): 11812-11817.

[26] Milder J C, Scherr S J, Bracer C. Trends and future potential of payment for ecosystem services to alleviate rural poverty in developing countries[J]. Ecology and Society, 2010, doi: 10. 1108/ 09653561011091922.

[27] Engel S, Pagiola S, Wunder S. Designing payments for environmental services in theory and practice: An overview of the issues[J]. Ecological Economics, 2008, 65(4): 663-674.

[28] 曹世雄, 陈莉, 余新晓. 陕北农民对退耕还林的意愿评价[J]. 应 用生态学报, 2009, 20(2): 426-434. [Cao S X, Chen L, Yu X X. Grain for green project: Willingness evaluation of the farmers in northern Shaanxi Province of China[J]. Chinese Journal of Applied Ecology, 2009, 20(2): 426-434.]

[29]杨娜, 李桦, 孙熠. 农户退耕成果维护意愿与行为一致性研究 [J]. 湖南农业大学学报(社会科学版), 2018, 19(5): 27-33. [Yang N, Li H, Sun Y. Consistency of farmer's maintenance willingness and behavior of returning farmland results[J]. Journal of Hunan Agricultural University (Social Sciences), 2018, 19(5): 27-33.]

[30] 陈奕山, 钟甫宁. 代际差异、长期非农收人与耕地转出稳定性 [J]. 南京农业大学学报(社会科学版), 2017, 17(3): 112-120. [Chen Y S, Zhong F N. Generation difference, long-term non-agriculture income and rural household's stable transfer out of contract land[J]. Journal of Nanjing Agricultural University (Social Sciences Edition), 2017, 17(3): 112-120.]

[31] 杨志海, 王雨濛. 不同代际农民耕地质量保护行为研究: 基于鄂
豫两省 829 户农户的调研[J]. 农业技术经济, 2015, (10): 48-56.

[Yang Z H, Wang Y M. Research on farmland quality protection behavior of farmers of different generations: Based on a survey of 829 households in Hubei Province and Henan Province[J]. Journal of Agrotechnical Economics, 2015, (10): 48-56.]

[32] 余威震, 罗小锋, 李容容, 等. 绿色认知视角下农户绿色技术采 纳意愿与行为悖离研究[J]. 资源科学, 2017, 39(8): 1573-1583. [Yu W Z, Luo X F, Li R R, et al. The paradox between farmer willingness and their adoption of green technology from the perspective of green cognition[J]. Resources Science, 2017, 39(8): 15731583.]

[33] Bauer R A. Consumer Behavior As Risk Taking[M]. Boston: Harvard Business Press, 1960.

[34] 齐琦, 周静, 王绪龙. 农户风险感知与施药行为的响应关系研 究: 基于辽宁省菜农数据的实证检验[J]. 农业技术经济, 2020, (2): 72-82. [Qi Q, Zhou J, Wang X L. Study on the relationship between farmer risk perception and pesticide application behavior response: An empirical test from vegetable farmers of Liaoning Province[J]. Journal of Agrotechnical Economics, 2020, (2): 72-82.]

[35] 邓正华, 张俊遥, 许志祥, 等. 农村生活环境整治中农户认知与 行为响应研究: 以洞庭湖湿地保护区水稻主产区为例「丁. 农业 技术经济, 2013, (2): 72-79. [Deng Z H, Zhang J B, Xu Z X, et al. Research on farmer's cognition and behavior response in rural living environment improvement: Taking Dongting Lake wetland reserve as an example[J]. Journal of Agrotechnical Economics, 2013, (2): 72-79.]

[36] 刘铮, 周静. 信息能力、环境风险感知与养殖户亲环境行为采 纳: 基于辽宁省肉鸡养殖户的实证检验[J]. 农业技术经济, 2018, (10): 135-144. [Liu Z, Zhou J. Information ability, perception of environmental risk and farmers' environmentally friendly behavior adoption: Based on empirical test of the sample of broiler farmers in Liaoning Province[J]. Journal of Agrotechnical Economics, 2018, (10): 135-144.]

[37] 王喜, 梁流涛, 陈常优. 不同类型农户参与耕地保护意愿差异分 析[J]. 干旱区资源与环境, 2015, 29(8): 52-56. [Wang X, Liang L $\mathrm{T}$, Chen $\mathrm{C}$ Y. The willingness of cultivated land protection for different households[J]. Journal of Arid Land Resources and Environment, 2015, 29(8): 52-56.]

[38] 刘炎周, 王芳, 郭艳, 等. 农民分化、代际差异与农房抵押贷款接 受度[J]. 中国农村经济, 2016, (9): 16-29. [Liu Y Z, Wang F, Guo $\mathrm{Y}$, et al. Differentiation of farmers, intergenerational difference and acceptance of rural housing mortgage[J]. Chinese Rural Economy, 2016, (9): 16-29.]

[39] 李军. 黄土高原地区种植制度研究[M]. 杨凌: 西北农林科技大 学出版社, 2004. [Li J. Study on Cropping System in Loess Plateau [M]. Yangling: Northwest Agriculture and Forestry University Press, 2004.] 


\title{
Influence of technology cognition and risk perception on the willingness to adopt soil and water conservation tillage technologies and its intergenerational differences
}

\author{
LIU Li' ${ }^{1,2}$, CHU Liqi', JIANG Zhide ${ }^{1}$ \\ (1. School of Economics and Management, Northwest Agriculture and Forestry University, Yangling 712100, China; \\ 2. College of History and Tourism Culture, Shanxi Normal University, Linfen 041000, China)
}

\begin{abstract}
Farmers' cognition and risk perception of soil and water loss are the key factors influencing adoption willingness for soil and water conservation tillage technology in the Loess Plateau. Exploring the effects of the two factors is conducive to improve technology adoption, control of soil and water loss, reduce sediment into the Yellow River and improve ecological environment. Based on the survey data of 1237 households in the Loess Plateau, this paper analyzes the impact of farmers' technology cognition and risk perception on willingness to adopt soil and water conservation tillage technology and the intergenerational differences by using stepwise regression and grouping regression. The results show that: (1) Technology cognition has a significant positive effect on adoption willingness, effect intensity of technology cognition on adoption willingness of new generations is greater than that of old generations for contour tillage, furrow and ridge planting, moderate or non-tillage, subsoiling, straw returning, stubble mulching and plastic film mulching. (2) Risk perception has a significant positive effect on willingness to adopt contour tillage and furrow and ridge planting, and the effect intensity is different between generations. Risk perception has a significant positive effect on willingness of new generations to adopt moderate or non-tillage, and on willingness of old generations to adopt subsoiling, straw returning, stubble mulching and plastic film mulching. (3) Risk perception plays a positive moderating role between technology cognition and adoption willingness. In willingness to adopt contour tillage, furrow and ridge planting, stubble covering and plastic film mulching technology, risk perception plays a stronger moderating role for old generations than for new generations. In willingness to adopt moderate or non-tillage, subsoiling and straw returning technology, risk perception plays a stronger moderating role for new generations than for old generations. (4) The control variables such as the age of householder, education level, family labor force, non-agricultural income proportion, actual cultivated land area, distance from the village to the town and the traffic convenience have significant differences on the willingness for new generations and old generations to adopt the soil and water conservation tillage technology.
\end{abstract}

Key words: technology cognition; risk perception; households; soil and water conservation tillage technologies; adoption willingness; intergenerational difference; the Loess Plateau 